\title{
Prevalence and Trends of Hepatitis B, Hepatitis C and Human Immunodeficiency Viruses among Blood Donors in Islamabad, Pakistan 2005-2013
}

\author{
Hasan Abbas Zaheer ${ }^{1 *}$, Umar Saeed ${ }^{2}$, Yasir Waheed ${ }^{2}$, Saira Karimi ${ }^{3}$ and Usman Waheed ${ }^{1}$ \\ ${ }^{1}$ Safe Blood Transfusion Programme, Government of Pakistan. \\ ${ }^{2}$ Blood Transfusion Services, Pakistan Institute of Medical Sciences, Islamabad, Pakistan \\ ${ }^{3}$ Atta-ur-Rahman School of Applied BioSciences (ASAB), National University of Sciences and Technology (NUST), Pakistan \\ ${ }^{4}$ Department of Biotechnology, Faculty of Biological Sciences, Quaid-i-Azam University, Islamabad, Pakistan
}

\begin{abstract}
Background: Pakistan is a developing country of 190 million people with increased burden of infectious diseases. Hepatitis B virus (HBV), Hepatitis C virus (HCV) and Human Immunodeficiency virus (HIV) are the most important agents responsible for transfusion transmitted viral infections. Blood donors are considered as the healthiest population of a community and screening of HBV, HCV \& HIV in blood donors will reflect the true prevalence of these infections in a population.
\end{abstract}

Material and Methods: The study was conducted from July 2005 to July 2013 at Pakistan Institute of Medical Sciences (PIMS) hospital, Islamabad, Pakistan. 160,376 blood donors from the age 18 years to 60 years were enrolled in this study. Study was approved by the ethical review committee of PIMS hospital. All the samples were screened for Hepatitis B virus surface Antigen (HBsAg), anti-HCV and anti-HIV by fourth generation ELISA. Statistical analyses were carried out by using SPS software version 17.

Results: Among 160,376 donors, 157,920 (98.47\%) were replacement donors. The overall seroprevalence of (HBVsAg), anti-HCV and anti-HIV among blood donors were $2.35 \%, 3.26 \%$ \& $0.017 \%$ respectively. The prevalence of $\mathrm{HBV}$ and $\mathrm{HCV}$ co-infection was $0.084 \%$.

Conclusion: The prevalence of Hepatitis B, Hepatitis C and Human Immunodeficiency viruses are high in blood donors and should not be acceptable. There is a need to educate masses to increase the number of voluntary donors to meet the country's requirement of blood donation.

Keywords: Hepatitis B virus; Hepatitis C virus; Human Immunodeficiency virus; Blood donors; Pakistan

\section{Introduction}

Hepatitis B virus (HBV), Hepatitis C virus (HCV) and Human Immunodeficiency virus (HIV) are three most important agents responsible for Transfusion Transmitted Infections (TTIs), worldwide. Globally, the World Health Organization (WHO) has estimated 2 billion people living with $\mathrm{HBV}, 200$ million people infected with HCV and 33.4 million people infected with HIV [1-4]. The Centre for Disease Control and Prevention, USA (CDC) has reported HBV to be 10 and 100 times more infectious, compared to HCV and HIV respectively [5]. HBV infected patients are more likely to develop Hepatocellular carcinoma (HCC), compared to patients with HCV [6]. In a retrospective study conducted between 1992 and 2006 on 128,726 patients, the mortality rates due to HCV mono infection, HBV mono infection, HBV/HCV co-infection, HIV/HBV co-infection, HIV/HCV co-infection and $\mathrm{HIV} / \mathrm{HBV} / \mathrm{HCV}$ triple infection were $63.7 \%, 33 \%$, $2.6 \%, 0.2 \%, 0.5 \%$, and $<0.1 \%$ respectively [7].

In Pakistan, $\mathrm{HBV}$ infection rate is steadily increasing with an estimated nine million people currently living with HBV [8]. More than ten million people are HCV infected in Pakistan. According to an estimate, approximately 97,000 to 1, 25,000 persons are HIV Positive in Pakistan [9]. The prevalence of HBV, HCV, and HIV in blood donors of Pakistan has been reported to be $2.33 \%, 3.78 \%$, and $0.06 \%$ respectively [10-12]. Pakistan, a developing country with 190 million inhabitants, thus faces a high socioeconomic burden of infectious diseases. This is in addition to high prevalence of anemia, communicable diseases, malnutrition, thalassemia, obstetrical emergencies, traumatic injuries and road traffic accidents. In such circumstances, the demand for blood supply increases, and blood transfusion becomes lifesaving. According to an estimate, 3 million blood donations are carried out each year in Pakistan but unfortunately the country suffers shortage of blood and blood components [13]. In Islamabad, although the government is providing better health facilities to common people, yet due to lack of awareness among general public and non-implementation of health related safety standards at various hospitals, the prevalence of infectious diseases (HBV, HCV and HIV) is progressively increasing.

Due to the imbalance in the supply and demand, the quality of blood transfusion services has been adversely affected. The total number of blood banks is estimated to be 1830 with majority $(85.8 \%)$ of them in the private sector [13]. Most of the blood transfusion services are confined to hospitals, with no functional separation of the processes into production and utilization while majority of blood donations are offered by replacement blood donors. Screening for

*Corresponding author: Hasan Abbas Zaheer, Blood Transfusion Services, Pakistan Institute of Medical Sciences, Islamabad, Pakistan, Tel: 009233351238 14; Fax: 009251926 3238; E-mail: hazaheer@gmail.com

Received March 21, 2014; Accepted April 29, 2014; Published May 07, 2014

Citation: Zaheer HA, Saeed U, Waheed Y, Karimi S, Waheed U (2014) Prevalence and Trends of Hepatitis B, Hepatitis C and Human Immunodeficiency Viruses among Blood Donors in Islamabad, Pakistan 2005-2013. J Blood Disorders Transf 5: 217. doi: 10.4172/2155-9864.1000217

Copyright: (c) 2014 Zaheer HA, et al. This is an open-access article distributed under the terms of the Creative Commons Attribution License, which permits unrestricted use, distribution, and reproduction in any medium, provided the original author and source are credited. 
transfusion-transmissible infections (TTIs) is a critical part of the process of ensuring blood safety. Unsafe blood transfusion is very costly both from a human and an economic point of view. Inadequate blood supply has led to increase in reliance on replacement donations and in some centers to even paid donations. In addition, the cultural and socio economic factors are associated with reluctance to donate blood as solidarity is still 'biradari' based and normally takes the form of family replacement donation with blood being collected "just on time" in a hospital environment with no arrangement for donor or community interface management. In general, this model meets the demand, though at the potential risk of increased TTI infection rate [14]. Reporting of prevalence data on transfusion transmitted diseases among blood donors can provide an insight into the trends towards blood borne infections in blood donor populations and consequently determine safety of the collected blood donations. The aim of our study was to determine trends in prevalence of HBV, HCV and HIV infections during last eight years (2005-2013 years), among blood donors of capital cities (Islamabad and Rawalpindi) of Pakistan.

\section{Material and Methods}

A cross sectional study was conducted during the period of July 2005 to July 2013 among 160,376 health blood donors aged 18 to 60 at the Pakistan Institute of Medical Sciences (PIMS), Islamabad. PIMS is tertiary care teaching hospital that provides healthcare facilities to over 5 million inhabitants of Islamabad-Rawalpindi metropolitan area, adjoining areas and north of the country.

The ethical committee of Pakistan Institute of Medical Sciences (PIMS) approved the study proposal and protocol. Appropriate clinical examination for each participant was conducted while individuals with severe health complications were excluded from study. Informed written consent, medical and socio-demographic histories and donor history questionnaire containing previous history of blood transfusions and risky sexual behaviors of donors were collected from each enrolled participant.

$\mathrm{ABO}$ and Rhesus (Rh) blood typing were carried out by using monoclonal blood grouping antiserum; included anti-A, anti- $\mathrm{B}$, anti$\mathrm{AB}$ and anti-D. All donations were tested according to the standardized screening test algorithms for hepatitis B surface antigen ( $\mathrm{HBsAg}$ ), anti-HCV and anti-HIV. Initial screening was performed by fourthgeneration ELISA kits (Bio-kit). All reactive samples were repeated in duplicate. Repeat reactive sera were recognized as confirmed ELISA positive cases. The positive blood units were incinerated. Statistical analysis was carried out via Statistical Package for Social Sciences (SPSS) software version 17. Significance value was evaluated at 0.05 levels with $95 \%$ confidence level.

\section{Results}

The results of serological screening tests for HBV, HCV and HIV performed within the duration of 2005 to 2013, revealed continuously increasing trend of all infections. Among 160,376 healthy blood donors, 159,770 (99.62\%) were males and $606(0.38 \%)$ were females. The replacement blood donors were 157,920 (98.47\%) while volunteer blood donors were only 2,456 (1.53\%). The overall Seroprevalence of HBsAg, anti-HCV and anti-HIV among blood donors of IslamabadRawalpindi metropolitan area, for the duration of last eight years, were $3,776(2.35 \%), 5,222(3.26 \%)$ and $27(0.017 \%)$ respectively. HBV and HCV co-infection was observed among 135 participants with an overall prevalence of $0.084 \%$.

For analysis of change in trend, the data was segregated into group A comprising of cases from 2005 to $2009(n=71,896)$ and group B $(\mathrm{n}=88,480)$ spanning from 2010 till 2013. Analysis revealed a significant increase in prevalence of HBsAg, HCV and HIV respectively. The prevalence of HBsAg rose from $1.856 \%$ (1339 out of 71,896) in group A to $2.75 \%(2,437$ out of 88,480$)$ in group B $(\mathrm{P}<0.001)$. Similarly significant difference was observed between the two groups for prevalence of HCV and HIV (3.14\% vs. $3.35 \%$; $\mathrm{P}=0.005$ for $\mathrm{HCV}$ and $0.0069 \%$ vs. $0.025 \% ; \mathrm{P}<0.001$ for HIV) respectively. The prevalence of $\mathrm{HBV} / \mathrm{HCV}$ co-infection increased from $0.078 \%$ in group A to $0.09 \%$ in group B, during this period. The Figure 1 shows prevalence of HBsAg, Anti-HCV and Anti-HIV in blood donors during 2005-2013, while Table 1 represents type of donors and gender distribution.

\section{Discussion}

As a result of weak governance and regulation, the transfusion services in the country are not quality assured and standardized. The Blood Transfusion Authorities, regulatory bodies for inspection, licensing and data management, have been notified in all provinces but are still in their formative years. Transfusion transmitted infections

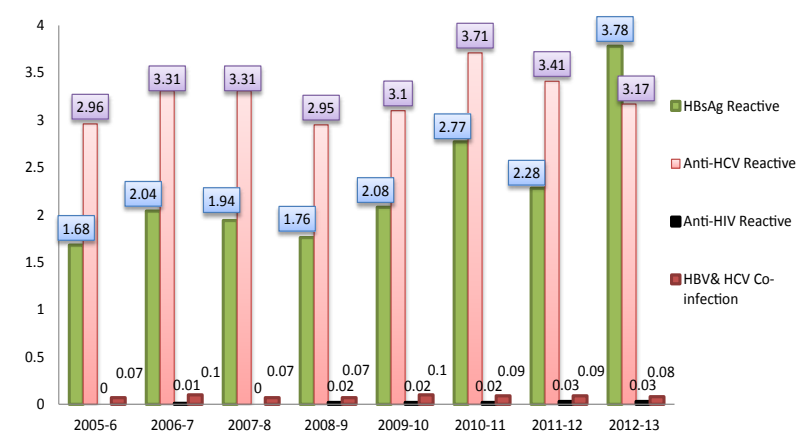

Figure 1: Prevalence of HBsAg, Anti-HCV and Anti-HIV in Blood Donors.

\begin{tabular}{|c|c|c|c|c|c|c|}
\hline Sr. No & Year & Total Donors & Volunteer (\%) & Replacement (\%) & Male (\%) & Female (\%) \\
\hline 1 & $2005-6$ & 15,213 & $1,374(9.03 \%)$ & $13,839(90.97 \%)$ & $14,907(98.0 \%)$ & $306(2.0 \%)$ \\
\hline 2 & $2006-7$ & 19,374 & $96(0.50 \%)$ & $19,278(99.50 \%)$ & $19,333(99.8 \%)$ & $41(0.2 \%)$ \\
\hline 3 & $2007-8$ & 18,241 & $210(1.15 \%)$ & $18,031(98.85 \%)$ & $18,207(99.8 \%)$ & $34(0.2 \%)$ \\
\hline 4 & $2008-9$ & 19,068 & $313(1.64 \%)$ & $18,755(98.36 \%)$ & $19,022(99.8 \%)$ & $46(0.2 \%)$ \\
\hline 5 & $2009-10$ & 19,862 & $187(0.94 \%)$ & $19,675(99.06 \%)$ & $19,794(99.7 \%)$ & $68(0.3 \%)$ \\
\hline 6 & $2010-11$ & 21,825 & $136(0.62 \%)$ & $21,689(99.38 \%)$ & $21,780(99.8 \%)$ & $45(0.2 \%)$ \\
\hline 7 & $2011-12$ & 23,377 & $46(0.20 \%)$ & $23,331(99.80 \%)$ & $23,346(99.9 \%)$ & $31(0.1 \%)$ \\
\hline Total & $2012-13$ & 23,416 & $94(0.40 \%)$ & $23,322(99.60 \%)$ & $23,381(99.85 \%)$ & $35(0.15 \%)$ \\
\hline
\end{tabular}

Table 1: Type of donors and gender distribution. 
are frequently detected among paid blood donors. Many developed nations have outlawed the use of paid blood donors in order to minimize the risk of transfusion-transmitted diseases. Since 1998, Chinese government banned paid blood donations and currently many blood banks are relying on voluntary blood donations. This strategy has significantly contributed in decline of high HCV prevalence from $8.68 \%$ (1990) to $3.2 \%$ (2010) in general population of China [15]. India, Pakistan's neighbor has also passed a law in 1998 to ban all paid donations and successfully managed to reduce prevalence of TTIs among blood donors. It has been reported that percentage prevalence of HBV, HCV and HIV in India, among blood donors reduced from $1.62 \%, 1.85 \%$ and $1.16 \%$ (in 2004 ) to $0.92 \%, 0.52 \%$ and $0.21 \%$ (in 2009 ) respectively [16]. Iran, Pakistan's neighbor has also managed to reduce percentage prevalence of TTIs among blood donors during 2003 to 2005. In Iran, the prevalence of HBV, HCV and HIV was $0.71 \%, 0.14 \%$ and $0.0033 \%$ respectively (in 2003), while its prevalence reduced to $0.48 \%, 0.023 \%$ and $0.0031 \%$ respectively (in 2005). In Afghanistan, 1 , 25,832 blood donors were tested during 1989 to 2005. Among those individuals, $1.76 \%$ and $0.63 \%$ were positive for HBsAg and Anti-HCV respectively [17].
According to Anwar et al, the prevalence of HBsAg and Anti-HCV was observed $7.94 \%$ and $2.79 \%$ respectively [18]. This study indicates constantly increasing burden of HBV, HCV and HIV among blood donors during the last eight years. Our study has identified that during the start of study (i.e. during 2005-6), among 15,213 blood donors, the prevalence of HBsAg, Anti-HCV and Anti-HIV were 1.68\%, 2.96\% and $0 \%$ respectively but during 2012-13 the prevalence of $\mathrm{HBV}, \mathrm{HCV}$ and HIV among 23,416 blood donors increased up to $3.78 \%, 3.17 \%, 0.08 \%$ respectively. In Pakistan, with an only incipient culture of voluntary donations, a strong reliance on replacement and the lack of systematic screening, the infection risks are increased, as family replacement donors are more likely to transmit transfusion-transmissible infections than are voluntary donors. Replacement blood donors are usually relatives and close friends who may hide their actual health status, in order to save lives of their loved ones [14]. For a nation to reach its basic blood requirements, at least $1 \%$ of population should donate blood [19]. It is estimated that average donation rate is only $0.37 \%$ and $0.75 \%$ in developing and transitional countries, compared to $3 \%$ in developed countries. The average number of blood donations per 1000 persons in low-income countries is 10 times lower as compared to the blood donations from developed countries $[14,19,20]$.

\begin{tabular}{|c|c|c|c|c|c|c|}
\hline Place of Study & Year of Study & Author & HBsAg Positive\% & Anti-HCV Positive \% & Population Type & References \\
\hline Lahore & 2000 & Majed et al. & $2.10 \%$ & & Blood Donors & [22] \\
\hline Lahore & 2002 & Rahman et al. & $2.25 \%$ & $4.10 \%$ & Blood Donors & {$[23,24]$} \\
\hline Lahore & 2005 & Sirhindi et al. & $3.36 \%$ & $4.16 \%$ & Blood Donors & [25] \\
\hline Lahore & 2007 & ljaz et al. & $1.52 \%$ & $5.34 \%$ & Blood Donors & [26] \\
\hline Lahore & 2007 & Sultan et al. & $1.46-2.99 \%$ & $3.01-4.99 \%$ & Blood Donors & {$[27]$} \\
\hline Lahore & 2009 & Manzoor et al. & $1.70 \%$ & $7.69 \%$ & Blood Donors & [28] \\
\hline Lahore & 2011 & Anwar et al. & $2.79 \%$ & $7.94 \%$ & Blood Donors & {$[18]$} \\
\hline Karachi & 2000 & Mujeeb et al. & $2.21 \%$ & $0.30 \%$ & Blood Donors & [29] \\
\hline Karachi & 2004 & Akhtar et al. & & $1.80 \%$ & Blood Donors & [30] \\
\hline Karachi & 2006 & Mujeeb et al. & $4.70 \%$ & $3.60 \%$ & Blood Donors & [31] \\
\hline Karachi & 2007 & Azam et al. & $4.50 \%$ & $4.36 \%$ & Blood Donors & [32] \\
\hline Karachi & 2008 & Mujeeb et al. & $6.20 \%$ & $7.50 \%$ & Blood Donors & [33] \\
\hline Karachi & 2008 & Nazar et al. & $1.71 \%$ & $2.06 \%$ & Blood Donors & [34] \\
\hline Karachi & $2004-11$ & Irfan et al. & $1.90 \%$ & $2.61 \%$ & Blood Donors & [35] \\
\hline Peshawar & 2000 & Ahmed et al. & $1.55 \%$ & & Blood Donors & [36] \\
\hline Peshawar & 2004 & Zaidi et al. & $1.40 \%$ & $1.34 \%$ & Blood Donors & [37] \\
\hline Peshawar & 2004 & Ahmed et al. & $1.90 \%$ & $2.20 \%$ & Blood Donors & [38] \\
\hline Peshawar & 2007 & Farooqi et al. & $2.54 \%$ & $3.21 \%$ & Blood Donors & [39] \\
\hline Peshawar & 2008 & Khattak et al. & & $4.10 \%$ & Blood Donors & [40] \\
\hline Peshawar & 2011 & Khan et al. & $2.07 \%$ & $0.89 \%$ & Blood Donors & {$[41]$} \\
\hline Peshawar & 2011 & Khan et al. & & $1.89 \%$ & Blood Donors & [42] \\
\hline Rawalpindi & 2002 & Mumtaz et al. & $5.86 \%$ & $6.21 \%$ & Blood Donors & [43] \\
\hline Rawalpindi & 2002 & Khattak et al. & $3.30 \%$ & $4.00 \%$ & Blood Donors & [44] \\
\hline Rawalpindi & 2006 & Chaudhary et al. & $2.45 \%$ & $2.52 \%$ & Blood Donors & {$[45]$} \\
\hline Rawalpindi & 2006 & Bhatti et al. & $2.16 \%$ & & Blood Donors & [46] \\
\hline Rawalpindi & 2007 & Khan et al. & $2.31 \%$ & $4.87 \%$ & Blood Donors & [47] \\
\hline Bahawalpur & 2002 & Fayyaz et al. & $7.53 \%$ & & Blood Donors & [48] \\
\hline Bahawalpur & 2006 & Fayyaz et al. & $2.69 \%$ & $2.52 \%$ & Blood Donors & [49] \\
\hline Quetta & 2003 & Ali et al. & & $1.87 \%$ & Blood Donors & [50] \\
\hline Quetta & 2007 & Khan et al. & $4.80 \%$ & $1.80 \%$ & Blood Donors & [51] \\
\hline Multan & 2004 & Mehmood et al. & $3.37 \%$ & $0.27 \%$ & Blood Donors & [52] \\
\hline Islamabad & 2004 & Asif et al. & $2.51 \%$ & $5.14 \%$ & Blood Donors & [53] \\
\hline Islamabad & 2009 & Waheed et al. & $1.92 \%$ & $3.31 \%$ & Blood Donors & [54] \\
\hline Skardu & 2006 & Aziz & $8.40 \%$ & $1.10 \%$ & Blood Donors & [55] \\
\hline Liaquetpur & 2006 & Khan et al. & $5.96 \%$ & $0.07 \%$ & Blood Donors & {$[56]$} \\
\hline Swat & 2006 & Ahmad & $1.11 \%$ & $2.23 \%$ & Blood Donors & [57] \\
\hline South Punjab & 2007 & Jehangir et al. & $4.93 \%$ & $4.06 \%$ & Blood Donors & {$[58]$} \\
\hline
\end{tabular}

Table 2: Prevalence of HBV and HCV among blood donors of different cities of Pakistan. 
Our data indicates gradual decrease in trend of volunteer blood donations during previous eight years. During 2005-6, 1,374 (9.03\%) volunteer blood donations were received, but after eight years, the number of voluntary blood donations decreased to $94(0.40 \%)$. Similarly, our data indicates gradual increase in reliance on replacement blood donations. During 2005-6, 13,839 (90.97\%) replacement blood donors were enrolled, but during 2012-13, their number increased to 23,322 (99.60\%). Current study indicates that during last eight years $98.46 \%$ were replacement blood donors, while voluntary blood donors were only $1.53 \%$. This data also suggests that with an increase in replacement blood donations and decreasing trend of voluntary blood donations, the percentage prevalence of transmission transmitted infections (HBV, HCV and HIV) also increases. In Pakistan, limited data on prevalence of HIV has been reported. The prevalence of HBV and HCV among blood donors varies in different regions of Pakistan as shown by Table 2 .

According to six different studies from Lahore (between 20002011), the prevalence of HBV among blood donors varied from $1.46 \%$ to $3.36 \%$, while the prevalence of HCV among blood donors ranged from $3.01 \%$ to $7.94 \%$. Similarly according to six different studies from Karachi (between 2000- 2008), the prevalence of HBV among blood donors varied from $1.71 \%$ to $6.20 \%$, while HCV prevalence ranged from $0.30 \%$ to $7.50 \%$. Seven different reports from Peshawar (between 2000 - 2011) indicated percentage prevalence of HBV, among blood donors, ranging from $1.40 \%$ to $2.54 \%$; while $\mathrm{HCV}$ prevalence varying from $0.89 \%$ to $3.21 \%$. Five different reports from Rawalpindi (between 2002- 2007) indicated HBV and HCV prevalence to be $2.16 \%-5.86 \%$ and $2.52 \%-6.21 \%$ respectively.

According to a World Bank report published in 2012, females are $49.19 \%$ (i.e. approximately $50 \%$ ) of the total Pakistani population [21]. In Pakistani society, large proportion of females are confined to house settings and therefore, are comparatively less exposed to risk factors associated with HBV, HCV and HIV as compared to males. Our results show that among 160,376 individuals who donated blood, only $0.38 \%$ were females. Currently, an inadequate surveillance system for sexually transmitted infections exists with inadequate identification of subpopulations where deadly viral pathogens are secretly propagating. One of the possible ways towards harm reduction in Pakistan is by supporting community organizations and NGOs [59]. World Health Organization advocates voluntary non-remunerated blood donors (VNRBD) to achieve blood safety. Provision of safe and adequate blood is the responsibility of the state and steps have to be taken to promote VNRBD awareness campaigns in Pakistan. The process of blood safety system reform was initiated in 2008by the government with the support of the German government through the platform of Safe Blood Transfusion Program (SBTP).

The SBT Program has drafted the Blood Safety Act 2013, which will provide uniform, up to date and comprehensive blood safety framework throughout the country and has been endorsed by all Health Departments. The new act promotes the concept of VNRND and proposes a centralized model of blood transfusion services in which blood donations and screening will be a task of Regional Blood Centers and hospitals will not be required to collect blood.

To promote the culture of voluntary blood donations the SBTP and PIMS Blood Bank have lately been involved in developing close collaboration with the university student's community in Islamabad. This initiative involves the formation of a Network of university based Blood Donor Organizations (BDOs) and providing them technical guidance and support. The aim of this exercise will be to make Islamabad the first city in Pakistan to have complete reliance on voluntary blood donors with gradual phasing of the practice of forcing the family members and friends of the patients to provide blood donations. This model can then be applied to other cities in a step-wise manner. We hope this project envisages strategies to promote VNRBD and also work in other priority areas to achieve the ultimate objective of blood safety. Improvements in the donor management practices would lead to increase in VNRBD, blood safety and reduction in recurrent costs of a blood center.

\section{Acknowledgement}

Mr. Bilal Ahmed Tareen, Manager Blood Transfusion Services, Pakistan Institute of Medical Sciences (PIMS), Islamabad.

\section{References}

1. (2013) World Health Organization (WHO) Hepatitis B. Fact sheet Number 204

2. (2011) Hepatitis C Articles. Global HCV.

3. (2011) United Nation Program on HIVIAIDS (UNAIDS). Global Factsheet; World AIDS day Getting to Zero.

4. (2012) World Health Organization (WHO) Global Health Observatory Data Repository Data on the size of the HIVIAIDS epidemic: Prevalence of HIV among adults.

5. (2010) The Centre for Disease Control and Prevention USA.

6. James L (2010) Causes of Death Among People with Hepatitis B and C.

7. Walter SR, Thein HH, Amin J, Gidding HF, Ward K, et al. (2011) Trends in mortality after diagnosis of hepatitis B or C infection: 1992-2006. J Hepatol 54: 879-886.

8. Ali M, Idrees M, Ali L, Hussain A, Ur Rehman I, et al. (2011) Hepatitis B virus in Pakistan: a systematic review of prevalence, risk factors, awareness status and genotypes. Virol J 8: 102

9. Waheed U, Hayat K, Ahmad B, Waheed Y, Zaheer HA (2013) Evaluation of HIV AIDS diagnostics kits and formulation of a testing strategy for Pakistan. J Clin Virol 56: 367-369.

10. Waheed Y, Shafi T, Safi SZ, Qadri I (2009) Hepatitis C virus in Pakistan: a systematic review of prevalence, genotypes and risk factors. World $J$ Gastroenterol 15: 5647-5653.

11. Waheed Y, Rahat TB, Safi SZ, Qadri I (2010) Epidemiological patterns and risk factors associated with hepatitis $B$ virus in Pakistani population. Asian Biomedicine 4: 547-554.

12. Sultan F1, Mehmood T, Mahmood MT (2007) Infectious pathogens in voluntee and replacement blood donors in Pakistan: a ten-year experience. Int $\mathrm{J}$ Infect Dis 11: 407-412

13. Zaheer HA, Waheed U, Farhan Y (2012) Adoption of WHO Standard Operating Procedures for Blood Screening in Hospitals of Islamabad, Pakistan. African Journal of Pharmacy and Pharmacology 6: 1-2

14. National AIDS Control Programme. National Blood Policy and Strategic Framework 2008-2012 for Blood Transfusion Services in Pakistan. Ministry of Inter-Provincial Coordination.

15. Fu Y, Xia W, Wang Y, Tian L, Pybus OG, et al. (2010) The seroprevalence of hepatitis $\mathrm{C}$ virus (HCV) among 559,890 first-time volunteer blood donors in China reflects regional heterogeneity in HCV prevalence and changes in blood donor recruitment models. Transfusion 50: 1505-1511.

16. Bhawani Y, Rao PR, Sudhakar V (2010) Seroprevalence of transfusion transmissible infections among blood donors in a tertiary care hospital of Andhra Pradesh. Biology and Medicine 2: 45-48.

17. Khan S1, Attaullah S (2011) Share of Afghanistan populace in hepatitis B and hepatitis C infection's pool: is it worthwhile? Virol J 8: 216.

18. (2009) World Health Organization. WHO Country Office in Pakistan: Blood Safety.

19. (2010) World Health Organization. Global blood safety and availability; Key facts and Figures.

20. (2013) Trading Economics Population; Female (\% of Total) in Pakistan. 
21. Majed A, Qayyum A (2000) Presence of hepatitis B virus in healthy donors at blood unit Punjab Institute of Cardiology, Lahore Pakistan. J Med Res 39 111-112.

22. Rahman MU, Akhtar G, Lodhi Y (2002) Transfusion transmitted HIV and HBV infections in Punjab, Pakistan. Pak J Med Sci 18: 18-25.

23. Rahman MU, Akhtar G, Lodhi Y (2002) Seroprevalence of Hepatitis-C antibodies in blood donors. Pak J Med Sci18: 193-196.

24. Sirhindi GA, Khan AA, Alam SS, Ghori MA, Rehman RU, et al. (2005) Frequency of Hepatitis B, C and Human Immunodeficiency virus in blood donors at Sheikh Zayed Hospital, Lahore. Proceeding Shaikh Zayed Postgrad Med Inst. 19: 33-36.

25. Ijaz AU, Shafiq F, Toosi NA, Malik MN, Qadeer R (2007) Hepatitis B and Hepatitis $C$ in blood donors: Analysis of 2-years data. Ann King Edward Med Coll 13: 59-61.

26. Sultan F1, Mehmood T, Mahmood MT (2007) Infectious pathogens in voluntee and replacement blood donors in Pakistan: a ten-year experience. Int J Infect Dis 11: 407-412.

27. Manzoor I, Hashmi N, Daud S, Ajmal S, Fatima H, et al. (2009) Seroprevalence of Transfusion Transmissible Infections (TTIS) in Blood Donors. Biomedica 25 154-158.

28. Farid SA, Siddiqi GM, Haq S, Khokar NG, Jaffery G (2011) Association of Blood Group Types to Hepatitis B and Hepatitis C Virus Infection. Biomedica 27:57-61.

29. Mujeeb SA, Aamir K, Mehmood K (2000) Seroprevalence of HBV, HCV and HIV infections among college going first time voluntary blood donors. J Pak Med Assoc 50: 269-270.

30. Akhtar S, Younus M, Adil S, Jafri SH, Hassan F (2004) Hepatitis C virus infection in asymptomatic male volunteer blood donors in Karachi, Pakistan. J Viral Hepat 11: 527-535.

31. Abdul Mujeeb S, Nanan D, Sabir S, Altaf A, Kadir M (2006) Hepatitis B and C infection in first-time blood donors in Karachi--a possible subgroup for sentinel surveillance. East Mediterr Health J 12: 735-741.

32. Azam M, Jamal N, Imtiaz F, Haque Z, Ayoob Z (2007) Blood donor screening for hepatitis and HIV. J Dow Uni Health Sci. 1: 82-83.

33. Mujeeb SA, Pearce MS (2008) Temporal trends in hepatitis B and C infection in family blood donors from interior Sindh, Pakistan. BMC Infect Dis 8: 43.

34. Nazar H, Nadia N, Shazia N, Zulfiqar A, Farhat A (2008) Prevalence of Hepatitis $B$ and $C$ in blood donors of Karachi. Biomedica 24: 116-117.

35. Irfan SM, Uddin J, Zaheer HA, Sultan S, Baig A (2013) Trends in transfusion transmitted infections among replacement blood donors in karachi, pakistan. Turk J Haematol 30: 163-167.

36. Ahmed F, Shah SH, Tariq M, Khan JA (2000) Prevalence of hepatitis B carrie and HIV in healthy blood donors at Ayub Teaching Hospital. Pakistan J Med Res 39: 91-92.

37. Zaidi A, Tariq WZ, Haider KA, Ali L, Sattar A, et al. (2004) Seroprevalence of hepatitis B, C and HIV in healthy blood donors in Northwest of Pakistan. Pak J Pathol 15:11-16.

38. Ahmad J, Taj AS, Rahim A, Shah A, Rehman M (2004) Frequency of Hepatitis $B$ and Hepatitis $C$ in healthy blood donors of NWFP: a single center experience. J Postgrad Med Inst 18: 343-352.

39. Farooqi JI, Farooqi RJ, Khan N, Mussarat (2007) Frequency of Hepatitis $B$ and $C$ in selected groups of population in NWFP, Pakistan. JPMI 21: 165-168.

40. Khattak MN, Akhtar S, Mahmud S, Roshan TM (2008) Factors influencing Hepatitis $C$ virus sero-prevalence among blood donors in North West Pakistan. J Public Health Policy 29: 207-225.

41. Khan A, Bukhari SS, Alvi MI, Qazi A (2011) Seroprevalence of Hepatitis B Hepatitis C and HIV in Blood Donors of Peshawar. Gomal J Med Sci 9: 46-50.

42. Khan NU, Ali I, Ahmad NU, Iqbal A, Rehman LU, et al. (2011) Prevalence of active HCV infection among the blood donors of Khyber Pakhtunkwa and FATA region of Pakistan and evaluation of the screening tests for anti-HCV. Virol $J$ 8: 154.

43. Mumtaz S, Rehman MU, Muzaffar M, Hassan MU, Iqbal W (2002) Frequency of Seropositive blood donors for hepatitis B, C and HIV viruses in railway hospital Rawalpindi. Pak J Med Res 41: 51-53.

44. Khattak MF, Salamat N, Bhatti FA, Qureshi TZ (2002) Seroprevalence of hepatitis B, C and HIV in blood donors in northern Pakistan. J Pak Med Assoc 52: $398-402$

45. Chaudhary IA, Ullah S, Khan SS, Masood R, Sardar MA, et al. (2007) Seroprevalence of Hepatitis $B$ and $C$ among the healthy blood donors at Fauji Foundation Hospital, Rawalpindi. Pak J Med Sci 23: 64-67.

46. Bhatti FA, Ullah Z, Salamat N, Ayub M, Ghani E (2007) Anti-hepatits B core antigen testing, viral markers, and occult hepatitis $B$ virus infection in Pakistan blood donors: implications for transfusion practice. Transfusion 47: 74-79.

47. Khan ZT, Asim S, Tariq Z, Ehsan IA, Malik RA, et al. (2007) Prevalence of Transfusion Transmitted Infections in Healthy Blood Donors in Rawalpind District, Pakistan-A Five Year Study. Int J Path 5: 21-25.

48. Fayyaz KM, Ali S, Khan AA, Shafique M, Khan MA, et al. (2002) Hepatitis B carrier among volunteer blood donor students at Quaid-i-Azam Medical College Bahawalpur. Professional Med J 9: 186-90.

49. Fayyaz M, Qazi MA, Ahmed G, Khan MA, Chaudhary GM (2006) Hepatitis B $C$ \& HIV; Sero-Prevalence of Infection in Blood Donors. Professional Med J 13: $632-636$

50. Ali N, Nadeem M, Qamar A, Qureshi AH, Ejaz A (2003) Frequency of Hepatitis $C$ virus antibodies in blood donors in Combined Military Hospital, Quetta. Pak J Med Sci 19: 41-44.

51. Khan ZA, Aslam MI, Ali S (2007) The Frequency of Hepatitis B and C among Volunteer Blood Donors in Balochistan. Hepatitis Monthly 7: 73-76.

52. Mehmood MA, Khawar S, Anjum H, Ahmed SM, Rafiq S (2004) Prevalence of Hepatitis B, C and HIV infection in blood donors of Multan region. Ann King Edward Med Coll 10: 459-461.

53. Asif N, Khokar N, llahi F (2004) Seroprevalence of HBV, HCV and HIV infection among voluntary non remunerated and replacement donors in Northern Pakistan. Pak J Med Sci 20: 24-8.

54. Waheed U, Zaheer HA, Naseem L, Hasan K (2009) Study of Hepatitis B and C virus seropositivity in healthy blood donors. Ann Pak Inst Med Sci 5: 233-236.

55. Aziz MS (2006) Prevalence of anti-Hepatitis C antibodies and Hepatitis B surface antigen in healthy blood donors in Baltistan. Pak Armed Forces Med J 56: 189-191.

56. Khan MA, Rehman A, Ashraf M, Ashraf M, Ali A, et al (2006) Prevalence of HBV, HCV and HIV in Blood Donors at Liaquerpur. Med J 13: 23-26.

57. Ahmad A (2006) Frequency of HBV surface Antigen and Anti-HCV in Healthy Voluntary Blood Donors in Swat District. JPMI 20: 187-190.

58. Jehangir W, Ali F, Shahnawaz U, Iqbal T, Qureshi HJ (2007) Prevalence of Hepatitis B, C and HIV in blood donors of South Punjab. SIMS J (Esculapio) 7: 6-7

59. Saeed U, Waheed Y, Manzoor S, Ashraf M (2013) Identification of novel silent HIV propagation routes in Pakistan. World J Virol 2: 136-138.
Citation: Nguyen DM, Brar R, Schrier SL, et al. (2014) The Varying Clinical Picture of Pure-White Cell Aplasia. J Blood Disorders Transf 5: 218, doi: 10.4172/2155-9864.1000218 